Article

\title{
The Microstructure, Mechanical Properties, and Corrosion Resistance of UNS S32707 Hyper-Duplex Stainless Steel Processed by Selective Laser Melting
}

\author{
Feng Shang ${ }^{1,2}$, Xiaoqiu Chen ${ }^{2}$, Zhiyong Wang ${ }^{2}$, Zuchun $\mathrm{Ji}^{3}{ }^{3}$, Fei Ming ${ }^{1}$, Shubin Ren ${ }^{1, *}$ and \\ Xuanhui Qu ${ }^{1, *(D)}$ \\ 1 Beijing Advanced Innovation Center for Materials Genome Engineering, University of Science and \\ Technology Beijing, Beijing 100083, China; shangfeng@hhit.edu.cn (F.S.); fryming@163.com (F.M.) \\ 2 School of Mechanical and Ocean Engineering, Jiangsu Ocean University, Lianyungang 222005, China; \\ cxq950808@163.com (X.C.); w19851821109@163.com (Z.W.) \\ 3 Mingyang Technology (Suzhou) Co., Ltd., Suzhou 215000, China; jzc110@126.com \\ * Correspondence: sbren@ustb.edu.cn (S.R.); quxh@ustb.edu.cn (X.Q.); \\ Tel.: +86-10-82377286 (S.R.); +86-10-62332700 (X.Q.)
}

Received: 15 August 2019; Accepted: 12 September 2019; Published: 17 September 2019

\begin{abstract}
UNS S32707 hyper-duplex stainless steel (HDSS) parts with complex shapes for ocean engineering were prepared by selective laser melting (SLM) process. In the process of SLM, the balance between austenite and ferrite was undermined due to the high melting temperature and rapid cooling rate, resulting in poor ductility and toughness. The solution annealing was carried out with various temperatures (1050-1200 ${ }^{\circ} \mathrm{C}$ ) for one hour at a time. The evolution of microstructures, mechanical properties, and corrosion resistance of UNS S32707 samples prepared by SLM was comprehensively investigated. The results indicate that a decrease in nitrogen content during the SLM process reduced the content of austenite, and a nearly balanced microstructure was obtained after appropriate solution annealing. The ratio between ferrite and austenite was approximately 59.5:40.5. The samples with solution treated at $1150{ }^{\circ} \mathrm{C}$ and $1100{ }^{\circ} \mathrm{C}$ exhibited better comprehensive mechanical properties and pitting resistance, respectively.
\end{abstract}

Keywords: selective laser melting; hyper-duplex stainless steel; microstructure; mechanical property; corrosion resistance

\section{Introduction}

The UNS S32707 hyper-duplex stainless steel (HDSS) has excellent mechanical properties and corrosion resistance. The pitting resistance equivalent number (PREN $=$ mass $\% \mathrm{Cr}+3.3 \mathrm{mass} \% \mathrm{Mo}+$ 16 mass $\% \mathrm{~N}$ ) is 49 , and the critical pitting temperature (CPT) is $90^{\circ} \mathrm{C}$. This material has been widely used in marine engineering equipment [1,2]. The hot working performance of the HDSS is poor due to the high content of $\mathrm{Cr}, \mathrm{Mo}$, and $\mathrm{N}$, leading to crack during hot rolling. Nitrogen escapes easily during welding, resulting in the performance of weld metal deteriorates [3,4]. In general, it is difficult to manufacture a duplex stainless steel, while the selective laser melting (SLM) is an effective technique to produce HDSS with the complex shapes. In detail, a higher relative density of duplex stainless steel can be obtained [5], and the precipitation of the $\sigma$ phase and other harmful phases can be inhibited due to a rapid cooling rate [6].

In recent years, the austenitic stainless steel [7], precipitation hardening stainless steel [8], martensitic stainless steel [9], high manganese steel [10], super-duplex stainless steel (SDSS) [11-14] 
prepared using SLM were studied. Although SLM technology has a certain basis for the preparation of SDSS, SLM of HDSS with higher nitrogen content has rarely been reported. Shang et al. [15] have shown that the microstructure of UNS S32707 HDSS prepared by SLM from the powder prepared by plasma rotating electrode process (PREP) is mainly ferrite. Although it has high strength and hardness, the ductility and toughness of duplex stainless steel are poor due to the precipitation of nitride at ferrite grain boundary. In this study, the microstructure, mechanical properties and corrosion resistance at different solution annealing temperatures were examined. The objective is to obtain an UNS S32707 HDSS prepared by SLM with balanced austenite-ferrite arrangement, ideal tensile strength, ductility, toughness, and corrosion resistance.

\section{Materials and Methods}

The PREP process of UNS S32707 HDSS powder, the SLM parameters, and the samples size can be found in Shang et al. [15]. The chemical composition of the powder is shown in Table 1, and the median diameter of the prepared metal powder was $45 \mu \mathrm{m}$. The samples were water-quenched using an atmosphere-protected quenching furnace (OTF-1500X-80-VTQ, Hefei Kejing Materials Technology Co., Ltd., Hefei, China) following solution annealing at 1050, 1100, 1150, and $1200{ }^{\circ} \mathrm{C}$, respectively. The sample numbers of different processing technologies are shown in Table 2.

Table 1. Chemical composition of UNS S32707 hyper-duplex stainless steel (HDSS) powder.

\begin{tabular}{ccccccccccccc}
\hline Element & $\mathbf{C r}$ & $\mathbf{N i}$ & $\mathbf{M o}$ & $\mathbf{N}$ & $\mathbf{S i}$ & $\mathbf{M n}$ & $\mathbf{C o}$ & $\mathbf{C u}$ & $\mathrm{Al}$ & $\mathbf{C}$ & $\mathbf{O}$ & $\mathbf{F e}$ \\
\hline mass $\%$ & 27.19 & 6.48 & 5.00 & 0.36 & 0.58 & 1.5 & 1.03 & 0.98 & 0.02 & 0.02 & 0.018 & Bal. \\
\hline
\end{tabular}

Table 2. The sample numbers of different processing technologies.

\begin{tabular}{cc}
\hline Processing Technology & $\begin{array}{c}\text { Sample } \\
\text { Number }\end{array}$ \\
SLM & S1 \\
SLM+ solution annealing $\left(1050^{\circ} \mathrm{C} \times 1 \mathrm{~h}\right)+$ water quenching & $\mathrm{S} 2$ \\
SLM+ solution annealing $\left(1100^{\circ} \mathrm{C} \times 1 \mathrm{~h}\right)+$ water quenching & $\mathrm{S} 3$ \\
$\mathrm{SLM}+$ solution annealing $\left(1150^{\circ} \mathrm{C} \times 1 \mathrm{~h}\right)+$ water quenching & $\mathrm{S} 4$ \\
SLM+ solution annealing $\left(1200^{\circ} \mathrm{C} \times 1 \mathrm{~h}\right)+$ water quenching & $\mathrm{S} 5$ \\
Casting bar UNS S32707 for PREP+ solution annealing $\left(1150{ }^{\circ} \mathrm{C} \times 1 \mathrm{~h}\right)+$ water quenching & $\mathrm{S} 6$ \\
Welded and seamless UNS S32707stainless steel pipe (ASTM A790) & $\mathrm{S} 7$ \\
\hline
\end{tabular}

The mechanical properties were measured by a WDW-10E microcomputer controlled electronic universal testing machine. The tensile specimens were built with a nominal gauge section of $25 \mathrm{~mm}$ length $\times 5 \mathrm{~mm}$ width $\times 2 \mathrm{~mm}$ thickness. Rectangular samples with the size of $55 \times 10 \times 10 \mathrm{~mm}$ were machined into V-notches for the impact test. The microhardness of the samples was measured by an HV-30 hardness tester. The nitrogen content in the powder and selective laser melted parts was measured by a LECO ONH 836 Oxygen Nitrogen Hydrogen Analyzer (LECO Corporation, St. Joseph, MI, USA).

The microstructure of the selective laser melted sample was observed by a Quanta 450 FEG scanning electron microscope (SEM) (FEI Company, Hillsboro, OR, USA). Prior to the SEM observations, the samples were electro etched in $10 \%$ oxalic acid at an operating voltage of $7 \mathrm{~V}$ for $25 \mathrm{~s}$. An HKL Channel5 electron backscatter diffraction (EBSD) analysis system (Oxford Instruments, Oxford, UK) equipped in an FEI Quanta 650F field emission scanning electron microscope (SEM) (FEI Company, Hillsboro, OR, USA) was used to obtain inverse pole figure mappings and phase mappings with a step size of $0.3 \mu \mathrm{m}$ and $0.5 \mu \mathrm{m}$ at an acceleration voltage of $20 \mathrm{kV}$ with a working distance of $13 \mathrm{~mm}$. The EBSD samples were polished by Leica EMRES 102 argon ion polishing instrument (Leica Microsystems, Wetzlar, Germany). The samples were first polished at a voltage of $5 \mathrm{kV}$ for $40 \mathrm{~min}$, and then polished at a voltage of $4.5 \mathrm{kV}$ for $50 \mathrm{~min}$. The angle of the ion gun was 15 degrees ( 2 ion 
guns). Finally, the voltage was reduced to $3.5 \mathrm{kV}$, and the polishing time was $60 \mathrm{~min}$ at low voltage with the same angle of the ion gun. The microstructure was observed by an FEI Tecnai G2 F20 transmission electron microscope (TEM) (FEI Company, Hillsboro, OR, USA). TEM samples were first mechanically polished to a thickness of about $50 \mu \mathrm{m}$, followed by ion-beam milling in a Gatan 691 precision ion polishing system (PIPS) at $5 \mathrm{kV}$ with a final polishing step at $1 \mathrm{kV}$ of ion energies. An FEI Super-energy dispersive spectrometer (EDS) system equipped in an FEI Titan Themis spherical aberration electron microscope (FEI Company, Hillsboro, OR, USA) was used for a high-resolution energy surface scan test. The effect of nitrogen content on the austenite content was simulated by JMatPro software (JMatPro 7.0, Sente Software Ltd., Guildford, UK). The simulated solution annealing temperature was $1150{ }^{\circ} \mathrm{C}$.

A Gill AC Bi-STAT electrochemical workstation was used to measure the potentiodynamic polarization curve at room temperature in $3.5 \% \mathrm{NaCl}$ solution. The classical three-electrode system is as follows: Saturated calomel electrode as the reference electrode, platinum electrode as the auxiliary electrode, and sample as the working electrode. The tests were recorded at a scan rate of $20 \mathrm{mV} / \mathrm{min}$ and ranged between -150 and $+2000 \mathrm{mV}$. Prior to the corrosion testing, the samples were electro polished in $10 \%$ oxalic acid at an operating voltage of $12 \mathrm{~V}$ for $25 \mathrm{~s}$. The composition of the passive film was analyzed by a Thermo Scientific ESCALAB 250Xi X-ray photoelectron spectroscopy (XPS) (Thermo Fisher Scientific Inc., Waltham, MA, USA), the source of X-ray excitation was Al $K_{\alpha}$, and the vacuum of analysis chamber was $10^{-9}$ mbar. The high resolution spectrum of XPS was resolved by PeakFit software (PeakFit 4.12, Seasolve Software Inc., Framingham, MA, USA).

\section{Results and Discussion}

\subsection{Microstructure}

The XRD diagrams of samples processed by different technologies are shown in Figure 1. It can be seen that the samples prepared by SLM are mainly composed of ferrite phase, whereas the solution treated samples at $1050^{\circ} \mathrm{C}$ were mainly composed of austenite and the $\sigma$ phase, and mainly composed of ferrite and austenite phases for samples treated at $1100-1200{ }^{\circ} \mathrm{C}$, respectively. The TEM bright-field image in Figure 2a shows that dislocations were found in the S1 sample, suggesting that the high stress caused by rapid cooling led to the appearance of dislocations. Dislocations provide a driving force for recrystallization during solution annealing [14]. The scanning transmission electron microscope-energy dispersive spectrometer (STEM-EDS) mapping of Figure $2 \mathrm{~b}, \mathrm{c}$ shows that the nanoscale $\mathrm{Cr}_{2} \mathrm{~N}$ were found at the ferrite grain boundary.

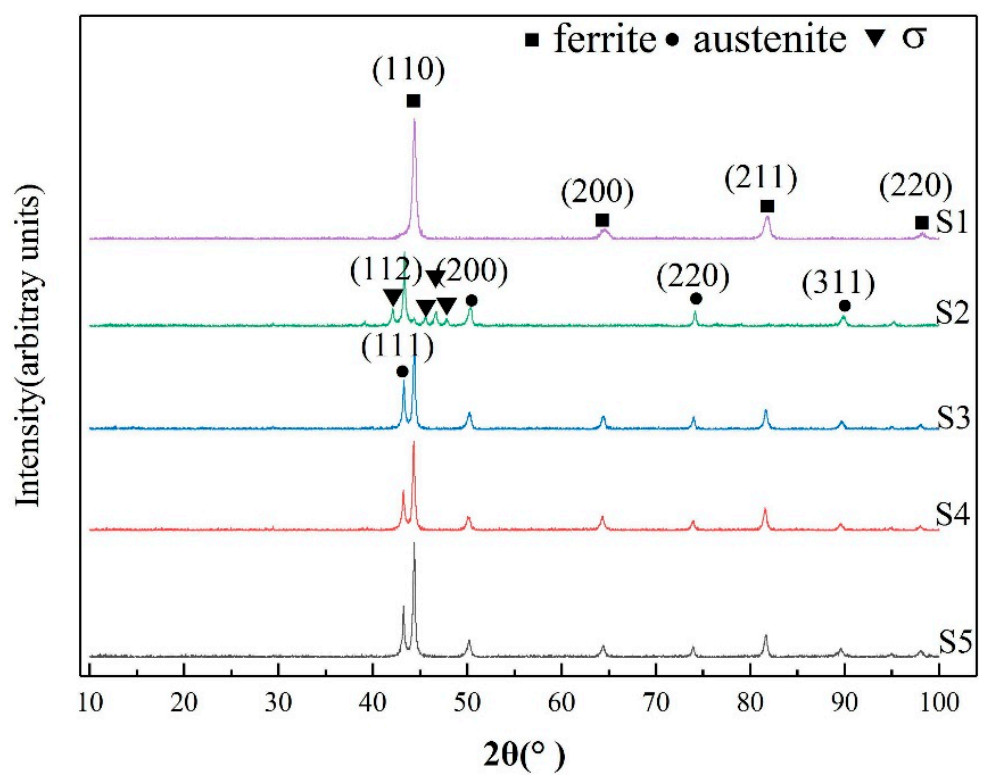

Figure 1. The XRD diagrams of samples processed by different technologies. 


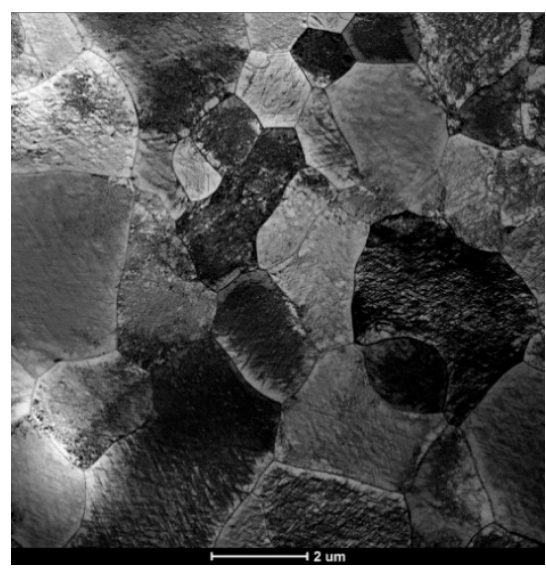

(a)

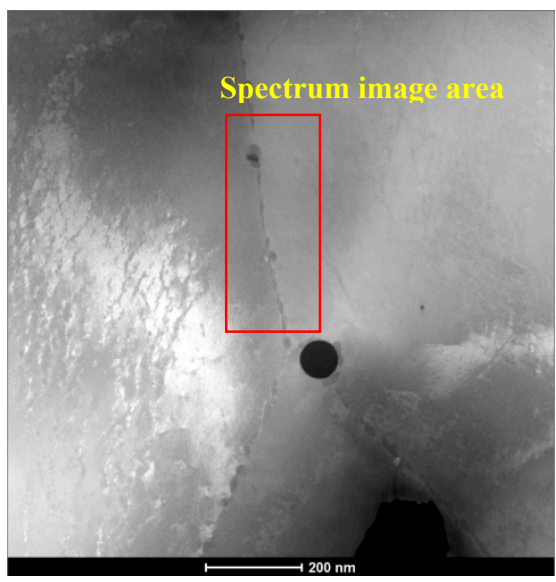

(b)
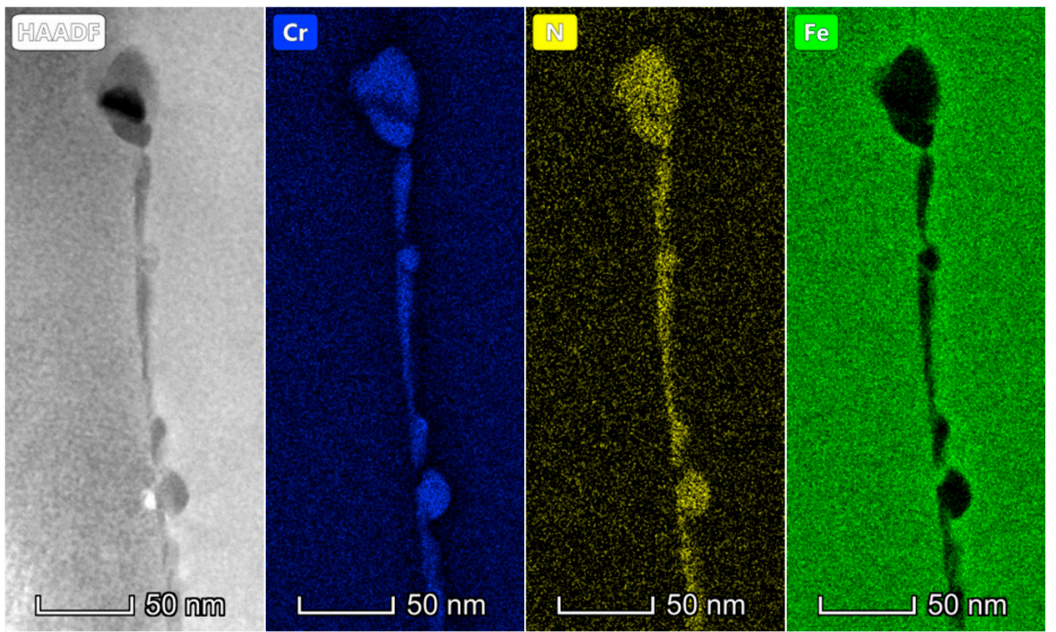

(c)

Figure 2. TEM morphology of the S1 sample (a) TEM bright field image; (b,c) scanning transmission electron microscope-energy dispersive spectrometer (STEM-EDS) mapping image.

The EBSD inverse pole diagram and phase distribution diagram of samples with different solution annealing processes are shown in Figure 3. Table 3 shows the proportion of phases and grain size of samples with different solution annealing processes. As shown in Figure 3, 10\% of the $\sigma$ phase and $88 \%$ of the $\gamma_{2}$ phase are precipitated from ferrite by eutectoid transformation [16,17]: $\alpha \rightarrow \sigma+\gamma_{2}$ at $1050{ }^{\circ} \mathrm{C}$. In the temperature range of $1100-1200{ }^{\circ} \mathrm{C}$, the grain size and the ferrite content increased gradually, while the austenite content decreased gradually with the increment in solution annealing temperature. The $\gamma_{2}$ phase nucleated only along the recrystallized ferrite grain boundary at $1200{ }^{\circ} \mathrm{C}$ [18]. The nitrogen content of HDSS powder decreased from $0.36 \%$ in powder state to $0.24 \%$ in selective laser melted state [15]. Nitrogen is an austenite-forming element, suggesting that its decrease resulted in the decrease of the austenite content after solution annealing, and it is not possible to achieve $50-50 \%$ ferrite-austenite ratio due to the nitrogen loss. Figure 4 shows the relationship between nitrogen content and austenite content of UNS S32707 HDSS simulated by JMatPro software. The simulated result shows that the decrease in nitrogen content reduced the austenite content by $10 \%$. 


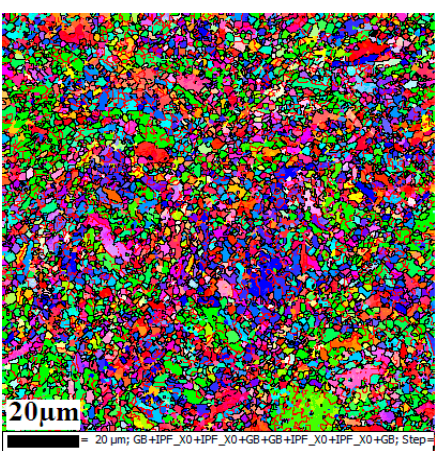

(a)

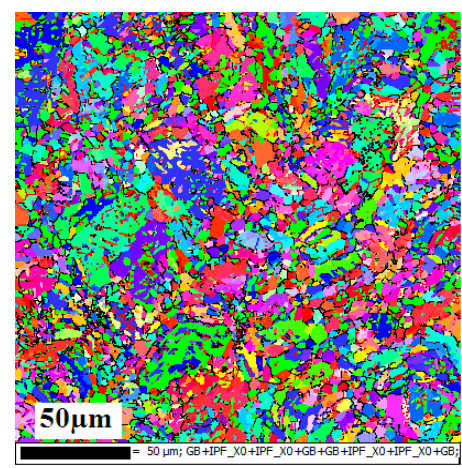

(b)

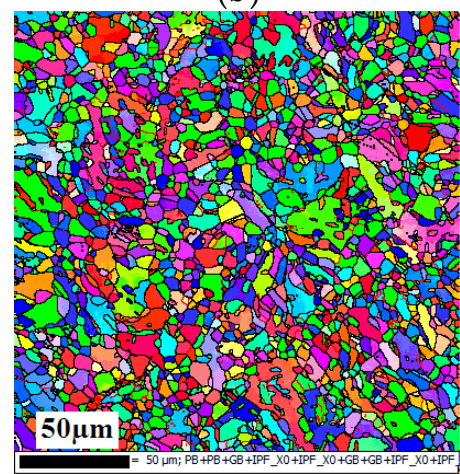

(c)

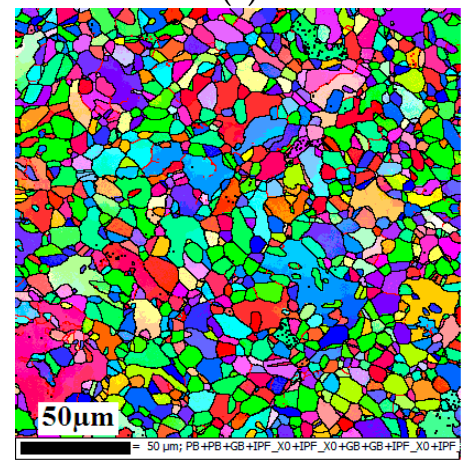

(d)

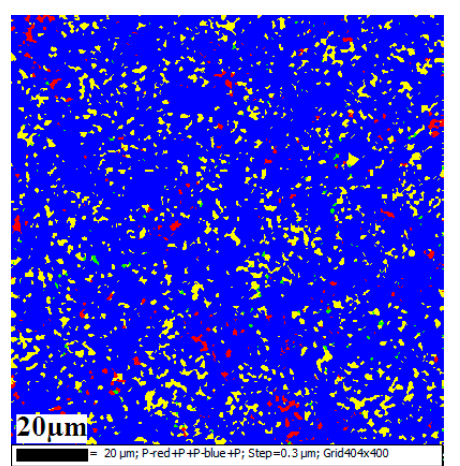

(e)

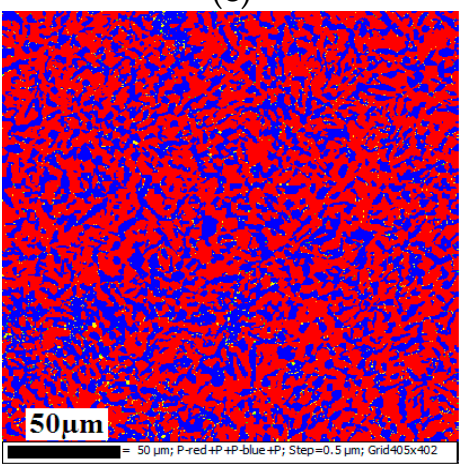

(f)

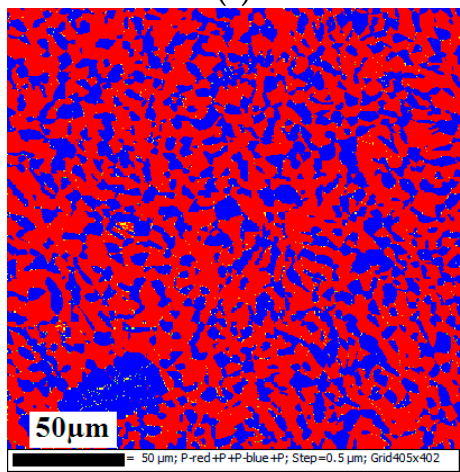

(g)

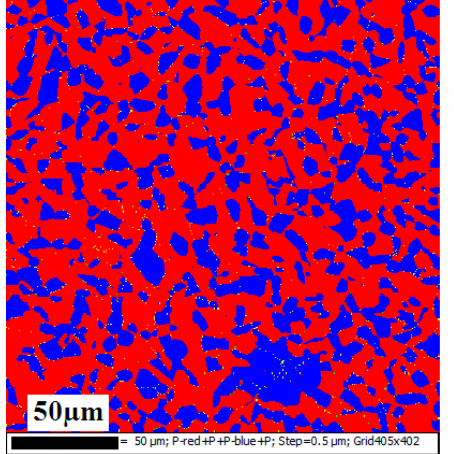

(h)
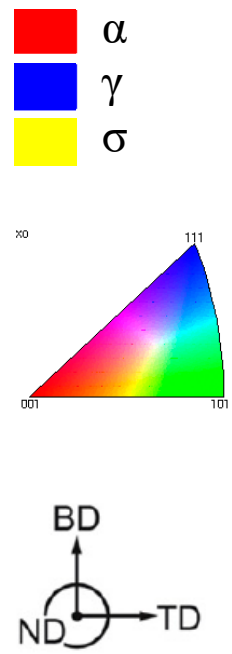

Figure 3. The electron backscatter diffraction (EBSD) diagram of different solution annealing processes (a-d) inverse pole figure and (e-h) phase distribution figure; (a,e) S2; (b,f) S3; (c, g) S4; (d,h) S5. 
Table 3. The proportion of phases and grain size of samples with different solution annealing processes.

\begin{tabular}{ccccccc}
\hline $\begin{array}{c}\text { Sample } \\
\text { Number }\end{array}$ & $\begin{array}{c}\text { The Content } \\
\text { of Ferrite } \\
\text { Phase/vol. \% }\end{array}$ & $\begin{array}{c}\text { Average } \\
\text { Grain } \\
\text { Size of } \\
\text { Ferrite/ } \mu \mathrm{mm}\end{array}$ & $\begin{array}{c}\text { The Content } \\
\text { of Austenite } \\
\text { Phase/vol. \% }\end{array}$ & $\begin{array}{c}\text { Average } \\
\text { Grain } \\
\text { Size of } \\
\text { Austenite/ } \mu \mathrm{m}\end{array}$ & $\begin{array}{c}\text { The Content } \\
\text { of Sigma } \\
\text { Phase/vol. \% }\end{array}$ & $\begin{array}{c}\text { Average } \\
\text { Grain Size } \\
\text { of Sigma } \\
\text { Phase/ } \mu \mathrm{mm}\end{array}$ \\
\hline S1 & 98.5 & 3.68 & 0.2 & 1.66 & - & - \\
S2 & 1.6 & 1.24 & 88.4 & 2.27 & 10.0 & 1.08 \\
S3 & 59.5 & 4.21 & 40.5 & 2.80 & - & - \\
S4 & 61.4 & 5.72 & 38.6 & 3.96 & - & - \\
S5 & 63.4 & 7.58 & 36.6 & 5.25 & - & - \\
\hline
\end{tabular}

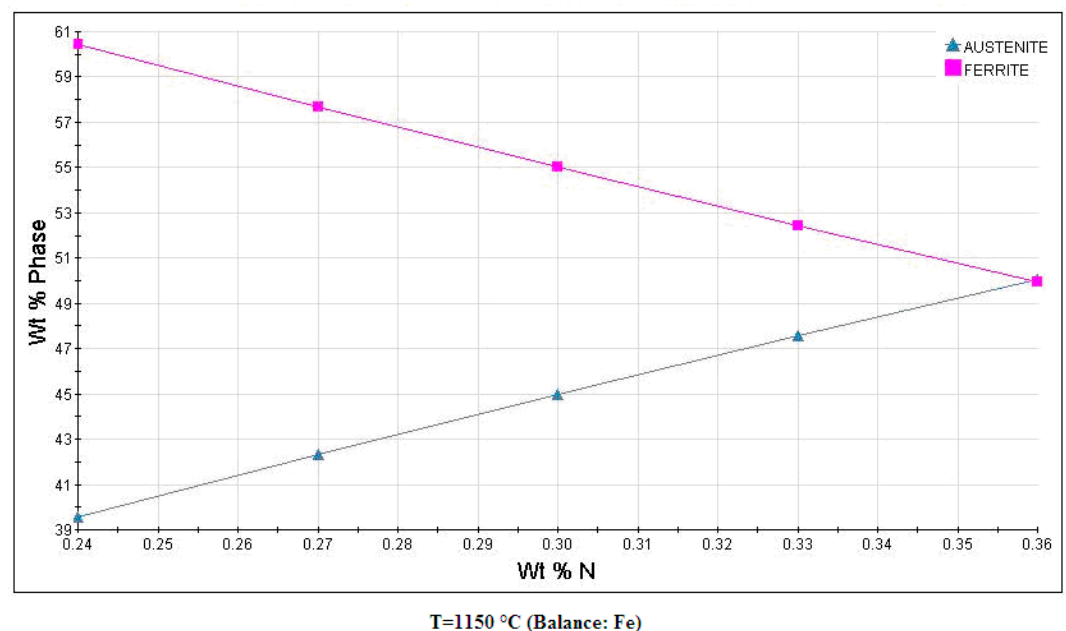

Figure 4. The relationship between nitrogen content and austenite content of UNS S32707 HDSS simulated by JMatPro software.

\subsection{Mechanical Properties}

Table 4 shows the mechanical properties of specimens processed with different conditions. The S1 specimen has high strength, hardness and relative density, relatively low ductility and toughness [15]. The strength and ductility of the $\mathrm{S} 2$ samples decrease rapidly due to the precipitation of the $\sigma$ phases. In the temperature range of $1100-1200{ }^{\circ} \mathrm{C}$, the strength and hardness decreased gradually while the elongation and section shrinkage increased gradually due to recrystallization and grain growth with the increase of solution annealing temperature. Lastly, the table also shows that the sample solution treated at $1150^{\circ} \mathrm{C}$ for one hour had better comprehensive mechanical properties compared to the others. Figure 5 is the tensile fracture and impact fracture morphology of the $S 4$ specimen, which is characterized by ductile fracture. There are some pores in the parts prepared by SLM with relative density of $98.2 \%$. The laser energy density, laser scanning strategy, and powder properties will affect relative density. In order to obtain fully compact parts, further densification by hot isostatic pressing can further improve the mechanical properties. Therefore, it is understandable that the mechanical properties prepared by SLM are lower than that of welded and seamless pipe required in ASTM A790 standard. 
Table 4. The mechanical properties of specimens processed under different conditions.

\begin{tabular}{ccccccc}
\hline $\begin{array}{c}\text { Sample } \\
\text { Number }\end{array}$ & $\begin{array}{c}\text { Tensile } \\
\text { Strength/MPa }\end{array}$ & $\begin{array}{c}\text { Yield } \\
\text { Strength/MPa }\end{array}$ & Elongation/\% & $\begin{array}{c}\text { Section } \\
\text { Shrinkage/\% }\end{array}$ & $\begin{array}{c}\text { Impact } \\
\text { Absorbing } \\
\text { Energy/J }\end{array}$ & Hardness/HV \\
\hline S1 & $1493 \pm 6$ & $1391 \pm 9$ & $13.2 \pm 1$ & $24.1 \pm 3$ & $18 \pm 3$ & $528.7 \pm 4$ \\
S2 & $593 \pm 20$ & - & - & - & - & $523.8 \pm 8$ \\
S3 & $941 \pm 10$ & $665 \pm 7$ & $24.6 \pm 2$ & $25.8 \pm 3$ & - & $321.8 \pm 7$ \\
S4 & $901 \pm 4$ & $658 \pm 10$ & $36.4 \pm 2$ & $48.4 \pm 2$ & $132 \pm 5$ & $291.5 \pm 6$ \\
S5 & $893 \pm 1$ & $646 \pm 3$ & $38.7 \pm 2$ & $52.6 \pm 3$ & - & $286.7 \pm 5$ \\
S6 & $851 \pm 7$ & $614 \pm 10$ & $29.2 \pm 2$ & $59.4 \pm 3$ & $128 \pm 6$ & $285.4 \pm 4$ \\
S7 & $920(\mathrm{~min})$ & $700(\mathrm{~min})$ & $25(\mathrm{~min})$ & - & - & 34 HRC (max) \\
\hline
\end{tabular}

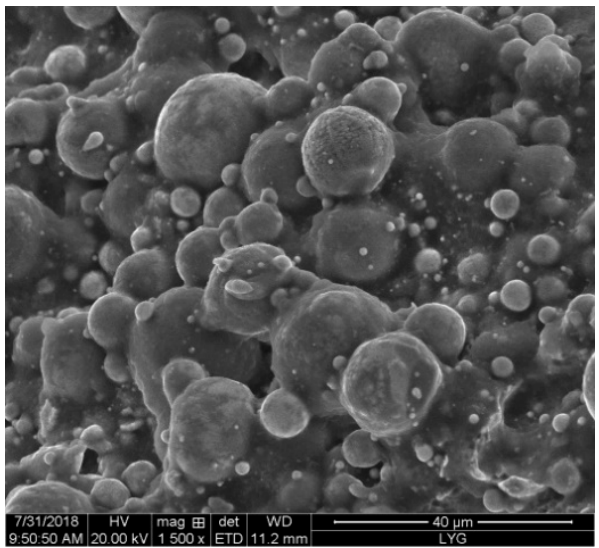

(a)

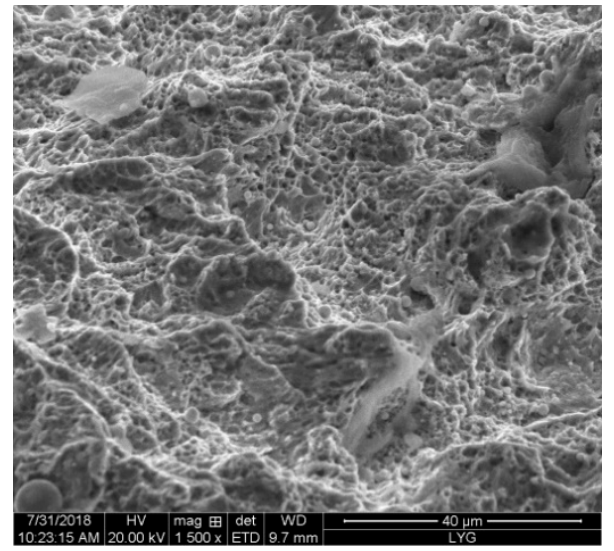

(b)

Figure 5. The fracture morphology of the $\mathrm{S} 4$ specimen (a) tensile fracture; (b) impact fracture.

\subsection{Corrosion Resistance}

Figure 6 shows the potentiodynamic polarization curve of samples processed with different conditions. The results of electrochemical experiments are shown in Table 5. Table 5 shows that the pitting potential of the $\mathrm{S} 3$ sample solution treated at $1100{ }^{\circ} \mathrm{C}$ for one hour was relatively higher $(1196 \mathrm{mV})$ compared to the others. The ratio of $\alpha$ to $\gamma$ of the S3 sample was 59.5:40.5. This suggests that good phase arrangement gave the material better pitting resistance. Table 5 also shows that the pitting potential of the S2 sample with $\sigma$ phase precipitation is the lowest $(1055 \mathrm{mV})$. Zhang et al. [19] studied the transformation mechanisms of the $\sigma$ phase in UNS S32707aged at nose temperature, the $\sigma$ phase preferentially formed along the $\alpha / \alpha$ and $\alpha / \gamma$ phase boundaries and then penetrated into $\alpha$ phase, resulting from the eutectoid reaction $\alpha \rightarrow \gamma_{2}+\sigma$. Meanwhile, a few $\sigma$ phases nucleated at the $\gamma / \gamma$ phase boundaries. The precipitation of the $\sigma$ phase in S2 may have led to poor $\mathrm{Cr}$ at $\alpha / \alpha, \alpha / \gamma, \gamma / \gamma, \alpha / \sigma$, and $\gamma / \sigma$ phase boundaries, which resulted in decreased pitting resistance. Figure 7 shows the EDS spectrum of the $\alpha$ and $\gamma$ phases in the S3 sample. The element distribution of the $\alpha$ and $\gamma$ phases is shown in Table 6. In the $\alpha$ phase, $\mathrm{Cr}$, Mo, and other $\alpha$-forming elements were enriched. In the $\gamma$ phase, the $\gamma$-forming element of $\mathrm{Ni}$ was enriched. The results of references $[20,21]$ show that the solubility of nitrogen in ferrite is generally less than $0.05 \%$. The ratio of $\alpha$ to $\gamma$ of the S3 sample was 59.5:40.5. It can be estimated that the nitrogen content of ferrite and austenite in the S3 sample is $0.05 \%$ and $0.52 \%$, respectively. The PREN (PREN $=$ mass $\% \mathrm{Cr}+3.3$ mass $\% \mathrm{Mo}+16$ mass $\% \mathrm{~N}$ ) of $\alpha$ and $\gamma$ were 50.7 and 50.6 , respectively. The pitting potential of the $\mathrm{S} 4$ and $\mathrm{S} 5$ samples is very close and difficult to distinguish. Figure 6 shows that the $\mathrm{S} 4$ sample presents a notable re-passivation process after its breakdown with the increment of the potential from 0.6 to $1.0 \mathrm{VSCE}$, while S5 shows a relatively higher dissolve rate with the increased potential from 0.6 to 1.1 VSCE. This indicates that the passive films of the S4 sample are much more stable than that of S5. Zheng et al. [22] found that more grain boundaries due to grain refinement could improve the chromium diffusion and promoted to the forming of compact passive 
film for the duplex stainless steel. In this study, the grain size of the S4 sample is smaller than that of S5, which is beneficial to the corrosion resistance of S4 with the refined grain size.

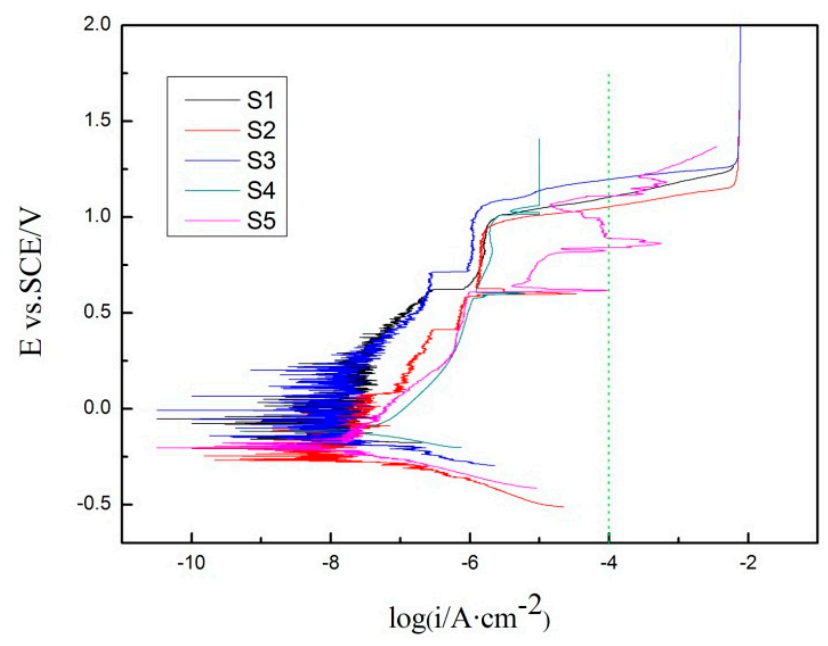

Figure 6. The potentiodynamic polarization curve of samples processed with different conditions.

Table 5. The results of electrochemical experiments.

\begin{tabular}{cc}
\hline Sample Number & Pitting Potential/mV \\
\hline S1 & 1109 \\
S2 & 1055 \\
S3 & 1196 \\
S4 & 1109 \\
S5 & 1109 \\
\hline
\end{tabular}

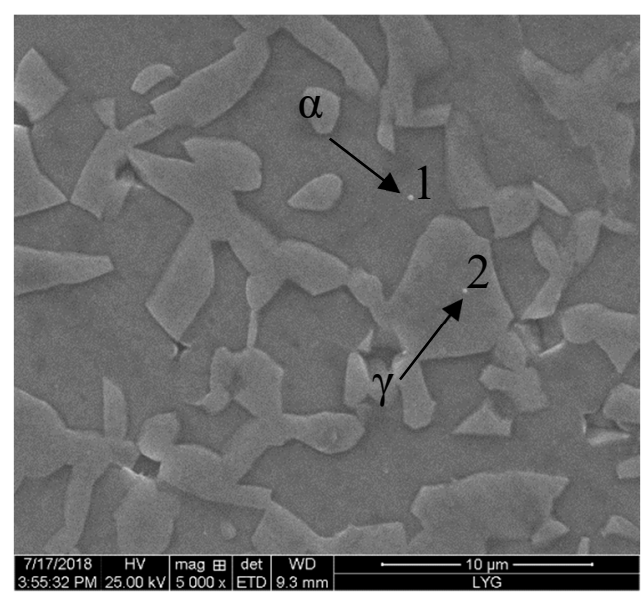

Figure 7. The EDS spectra of the S3 sample.

Table 6. The element distribution of the $\alpha$ and $\gamma$ phases (mass $\%$ ).

\begin{tabular}{cccccc}
\hline Phase & Fe & Cr & Ni & Mo & N \\
\hline$\alpha$ & 58.51 & 29.96 & 5.49 & 6.04 & 0.05 \\
$\gamma$ & 59.41 & 25.81 & 9.78 & 5.00 & 0.52 \\
\hline
\end{tabular}

Figure 8 shows the full spectrum of XPS on the surface of the S3 sample after solution annealing at different sputtering depths. As shown in Figure 8a, C, O, N, Fe, and $\mathrm{Cr}$ were notable, while Mo and $\mathrm{Ni}$ were weak before sputtering. Furthermore, Figure 8 shows that the surface of the passivation film is mainly composed of compounds formed by Fe, Cr, N, and $\mathrm{O}$. As shown in Figure 8b,c, the intensity 
of $\mathrm{C} 1$ s peak decreases greatly after sputtering, which indicate that the $\mathrm{C}$ peak in Figure 8a comes from the contamination of the vacuum chamber. The decrease of N1s peak indicates that $\mathrm{N}$ was mainly concentrated on the surface of the passive film. The strong peaks at the positions of Fe2p and Ni2p indicate that $\mathrm{Fe}$ and Ni elements mainly existed in the interior of the passive film. Lastly, Figure 8 also shows that the XPS spectra of the samples remain after different sputtering depths (1 nm and $2 \mathrm{~nm})$, indicating that the chemical composition of the passivation film was relatively stable in the thickness of $1 \mathrm{~nm}$ to $2 \mathrm{~nm}$.

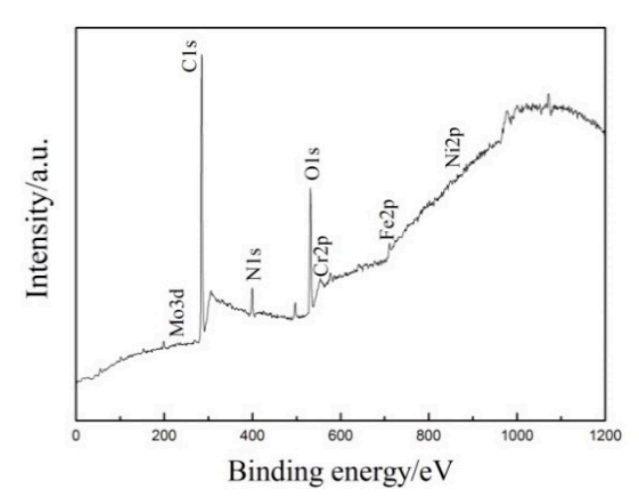

(a)

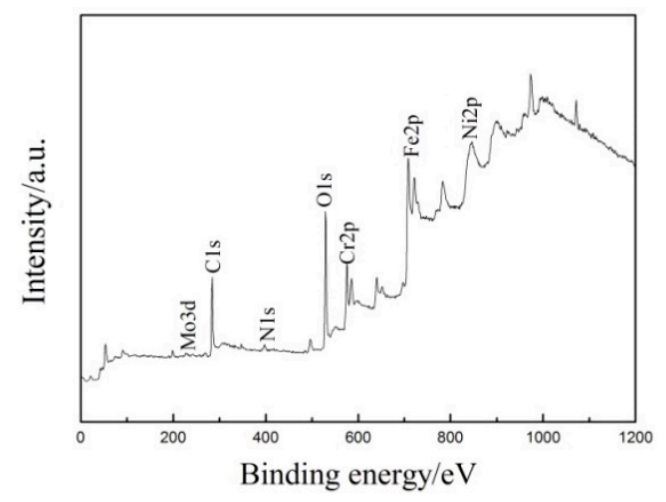

(b)

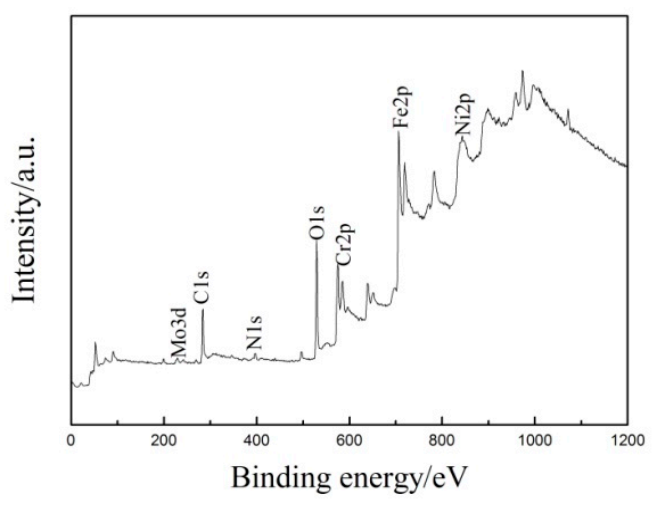

(c)

Figure 8. XPS full spectrum of the S3 sample after solution annealing with different sputtering depths (a) $0 \mathrm{~nm}$; (b) $1 \mathrm{~nm}$; (c) $2 \mathrm{~nm}$.

Figure 9 shows the result of the high-resolution XPS spectrum of O1s at different sputtering depths by PeakFit. As shown in Figure 9a, XPS spectra of O1s had three peaks before sputtering, corresponding to binding energies 529.5, 531.3, and $533.1 \mathrm{eV}$, respectively. According to the binding energy values of O1s reported by Wang et al. [23], the first peak is the characteristic peak of M-O compound, corresponding to $\mathrm{O}^{2-}$, the second peak is the characteristic peak of $\mathrm{M}-(\mathrm{OH})$ or $\mathrm{M}-(\mathrm{OH})_{2}$ compound, corresponding to $\mathrm{OH}^{-}$, and the third peak is the characteristic peak of $\mathrm{H}_{2} \mathrm{O}$. The characteristic peak of $533.1 \mathrm{eV}$ disappeared after sputtering, indicating that the water on the surface of the passivation film came from residual water on the electrode surface. From Figure $9 b, c$, it can be seen that the $\mathrm{O} 1 \mathrm{~s}$ high-resolution spectra of sputtered samples only had a characteristic peak of $\mathrm{O}^{2-}$ after spectral analysis, which indicates that oxygen in the passive films mainly exists in the form of oxides. 


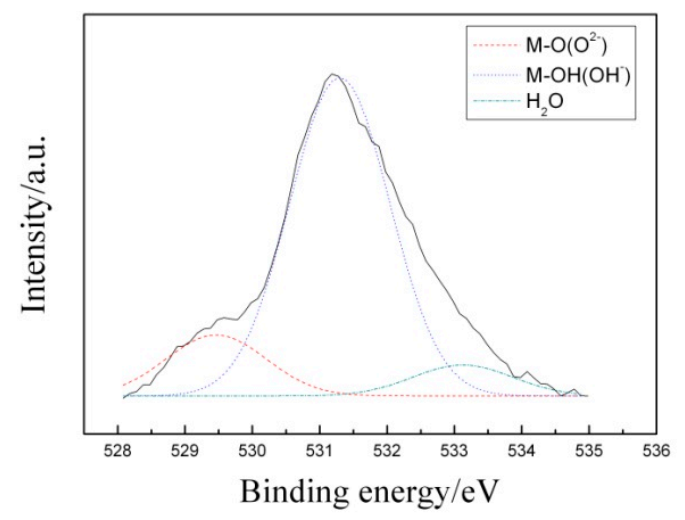

(a)

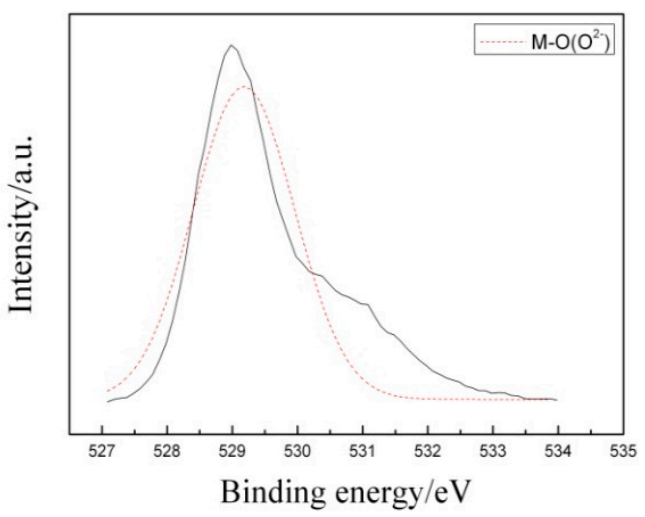

(b)

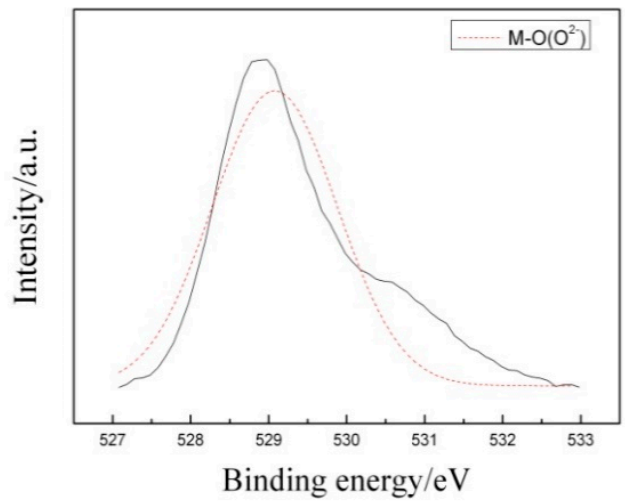

(c)

Figure 9. Narrow XPS of O1s with different sputtering depths (a) $0 \mathrm{~nm}$; (b) $1 \mathrm{~nm}$; (c) $2 \mathrm{~nm}$.

Figure 10 shows the high resolution XPS spectra of Mo3d $\mathrm{d}_{5 / 2}$ and N1s with different sputtering depths. Mo mainly exists in the form of $\mathrm{Mo}_{4}{ }^{2-}$ with a corresponding binding energy of $231.8 \mathrm{eV}$ before sputtering. When sputtering depth is 1 and $2 \mathrm{~nm}$, Mo mainly exists in $\mathrm{MoO}_{2}$ form with a corresponding binding energy of $231.2 \mathrm{eV}$. N mainly exists in the form of $\mathrm{NH}_{4}{ }^{+}$with a corresponding binding energy of $399.8 \mathrm{eV}$ before sputtering. When the sputtering depth is $2 \mathrm{~nm}$, the peak of $\mathrm{NH}_{4}{ }^{+}$disappears and $\mathrm{N}$ exists in the form of $\mathrm{Cr}_{2} \mathrm{~N}$ with a corresponding binding energy of $397.5 \mathrm{eV}$.

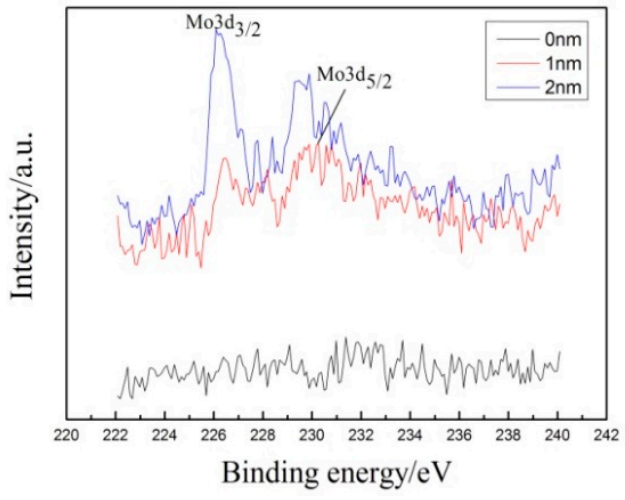

(a)

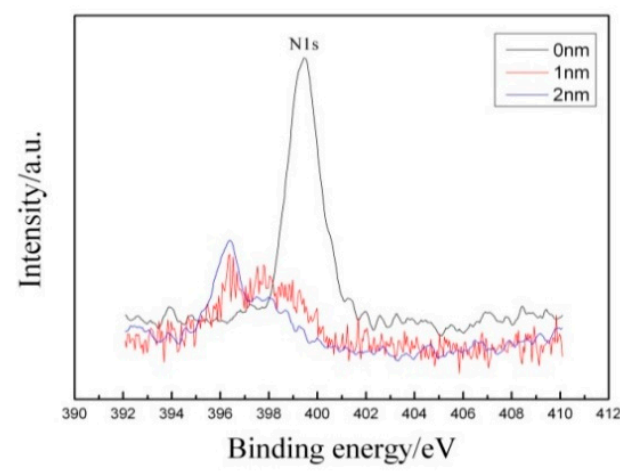

(b)

Figure 10. The high resolution XPS spectra of $\operatorname{Mo3d}_{5 / 2}(\mathbf{a})$ and N1s (b) at different sputtering depths.

\section{Conclusions}

This study has shown that UNS S32707 HDSS prepared by the SLM process can obtain a nearly balanced two-phase structure of ferrite and austenite through the appropriate solution annealing 
process, which can significantly improve the ductility and toughness. The nitrogen content reduced by $33 \%$ in the SLM process, resulting in the imbalance of the two phases and the reduction of the austenite content. The samples with solution treated at $1150{ }^{\circ} \mathrm{C}$ for one hour had better comprehensive mechanical properties, the measured tensile strength, the yield strength, the elongation, the section shrinkage, the microhardness, and the impact absorption energy were $901 \mathrm{MPa}, 658 \mathrm{MPa}, 36.4 \%, 48.4 \%$, $291.5 \mathrm{HV}$, and $132 \mathrm{~J}$, respectively.

The samples with solution treated at $1100^{\circ} \mathrm{C}$ for one hour had better pitting resistance. The pitting potential was $1196 \mathrm{mV}$. The surface layer of passive film is mainly composed of oxides of $\mathrm{Fe}$ and $\mathrm{Cr}$ and hydroxide compounds. $\mathrm{NH}_{4}{ }^{+}$adsorbed on the surface of passive film and protected the passive film. The inner layer of the passive film is mainly composed of metal elements, $\mathrm{Cr}_{2} \mathrm{~N}$ and oxides of $\mathrm{Fe}$, Cr, and Mo.

Author Contributions: F.S. is the first author and analyzed the data and wrote the paper. The experiments were performed by X.C., Z.W., Z.J., and F.M., S.R. and X.Q. conceived, designed, and supervised the experiments. In addition, they contributed to the interpretation of data and editing the paper.

Funding: This study was financially supported by the National Science and Technology Support Program of the Ministry of Science and Technology of China (No.2015BAE03B00), National Natural Science Foundation of China (No.51874038), Fundamental Research Funds for the Central Universities (FRF-AT-18-014), the Natural Science Foundation of Huaihai Institute of Technology (Z2017001), Lianyungang 521 Project (ZKK201805) and Lianyungang Haiyan Project (2018-QD-013).

Acknowledgments: We thank Jiasheng Dong and research fellow Langhong Lou from Shenyang Zhongke Sannai New Materials Co., Ltd. for his help in alloy melting. We thank Shujin Liang from Sino-Euro Materials Technologies of Xi'an Co., Ltd. for his help in PREP. We thank Xiaoming Zhang and Xuehao Zheng from ZKKF (Beijing) Science and Technology Co., Ltd. for TEM and EBSD observations.

Conflicts of Interest: The authors declare no conflict of interest.

\section{References}

1. Chail, G.C.; Kangas, P. Super and hyper duplex stainless steels: Structures, properties and applications. Procedia Struct. Integr. 2016, 2, 1755-1762. [CrossRef]

2. Song, Z.G.; Feng, H.; Hu, S.M. Development of Chinese duplex stainless steel in recent years. J. Iron Steel Res. Int. 2017, 24, 121-130. [CrossRef]

3. Pilhagen, J.; Sieurin, H.; Sandström, R. Fracture toughness of a welded super duplex stainless steel. Mater. Sci. Eng. A 2014, 606, 40-45. [CrossRef]

4. Kim, H.J.; Jeon, S.H.; Kim, S.T.; Park, Y.S. Influence of the shielding gas composition on the passive film and erosion corrosion of tube-to-tube sheet welds of hyper duplex stainless steel. Corros. Sci. 2015, 91, 140-150. [CrossRef]

5. Saeidi, K.; Kevetkova, L.; Lofaj, F.; Shen, Z. Novel ferritic stainless steel formed by laser melting from duplex stainless steel powder with advanced mechanical properties and high ductility. Mater. Sci. Eng. A 2016, 665, 59-65. [CrossRef]

6. Martín, F.; García, C.; Blanco, Y.; Rodriguez-Mendez, M.L. Influence of sinter-cooling rate on the mechanical properties of powder metallurgy austenitic, ferritic, and duplex stainless steels sintered in vacuum. Mater. Sci. Eng. A 2015, 642, 360-365. [CrossRef]

7. Trelewicz, J.R.; Halada, G.P.; Donaldson, O.K.; Manogharan, G.P. Microstructure and corrosion resistance of laser additively manufactured 316L stainless steel. JOM 2016, 68, 850-859. [CrossRef]

8. Akita, M.; Uematsu, Y.; Kakiuchi, T.; Nakajima, M.; Kawaguchi, R. Defect-dominated fatigue behavior in type 630 stainless steel fabricated by selective laser melting. Mater. Sci. Eng. A 2016, 666, 19-26. [CrossRef]

9. Krakhmalev, P.; Yadroitsava, I.; Fredriksson, G.; Yadroitsev, I. In situ heat treatment in selective laser melted martensitic AISI420 stainless steels. Mater. Design. 2015, 87, 380-385. [CrossRef]

10. Haase, C.; Bültmann, J.; Hof, J.; Ziegler, S.; Bremen, S.; Hinke, C.; Schwedt, A.; Prahl, U.; Bleck, W. Exploiting process-related advantages of selective laser melting for the production of high-manganese steel. Materials 2017, 10, 56. [CrossRef]

11. Davidson, K.P.; Singamneni, S. Magnetic characterization of selective laser-melted Saf 2507 duplex stainless steel. JOM 2017, 69, 569-574. [CrossRef] 
12. Davidson, K.P.; Singamneni, S. Selective laser melting of duplex stainless steel powders: An investigation. Manuf. Processes. 2016, 31, 1543-1555. [CrossRef]

13. Davidson, K.P.; Singamneni, S. Metallographic evaluation of duplex stainless steel powders processed by selective laser melting. Rapid. Prototyping. J. 2017, 23, 1146-1163. [CrossRef]

14. Hengsbach, F.; Koppa, P.; Duschik, K.; Holzweissig, M.J.; Burns, M.; Nellesen, J.; Tillmann, W.; Troster, T.; Hoyer, K.P.; Schaper, M. Duplex stainless steel fabricated by selective laser melting-Microstructural and mechanical properties. Mater. Design. 2017, 133, 136-142. [CrossRef]

15. Shang, F.; Chen, X.Q.; Zhang, P.; Ji, Z.C.; Ming, F.; Ren, S.B.; Qu, X.H. Novel Ferritic Stainless Steel with Advanced Mechanical Properties and Significant Magnetic Responses Processed by Selective Laser Melting. Mater. Trans. 2019, 60, 1096-1102. [CrossRef]

16. Topolska, S.; Labanowski, J. Effect of microstructure on impact toughness of duplex and superduplex stainless steels. J. Ach. Mater. Manuf. Eng. 2009, 36, 142-149.

17. Chan, K.W.; Tjong, S.C. Effect of secondary phase precipitation on the corrosion behavior of duplex stainless steels. Materials 2014, 7, 5268-5304. [CrossRef] [PubMed]

18. Maki, T.; Furuhara, T.; Tsuzaki, K. Microstructure development by thermomechnical processing in duplex stainless steel. ISIJ Int. 2001, 41, 571-579. [CrossRef]

19. Zhang, B.B.; Jiang, Z.H.; Li, H.B.; Zhang, S.C.; Feng, H.; Li, H. Precipitation behavior and phase transformation of hyper duplex stainless steel UNS S32707 at nose temperature. Mater. Charact. 2017, 129, 31-39. [CrossRef]

20. Ha, H.Y.; Jang, M.H.; Lee, T.H.; Moon, J.O. Interpretation of the relation between ferrite fraction and pitting corrosion resistance of commercial 2205 duplex stainless steel. Corros. Sci. 2014, 89, 154-162. [CrossRef]

21. He, Y.J.; Guo, X.Y.; Wu, Y.M.; Jiang, J.; Li, J. Effect of solution annealing temperature on pitting behavior of duplex stainless steel 2204 in chloride solutions. J. Iron Steel Res. Int. 2016, 23, 357-363. [CrossRef]

22. Zheng, Z.J.; Gao, Y.; Gui, Y.; Zhu, M. Corrosion behaviour of nanocrystalline 304 stainless steel prepared by equal channel angular pressing. Corros. Sci. 2012, 54, 60-67. [CrossRef]

23. Wang, Z.C.; Zhang, Y.Z.; Zhou, S.M. Corrosion compositions of carbon steel under ion-selective coatings by XPS. J. Chin. Soc. Corros. Prot. 2001, 21, 273-279. [CrossRef] 